\title{
Characterizing the Chemical Composition of Lipophilic Extracts from Acacia mearnsii Wood
}

\author{
Gliciane R. A. Oliveira, ${ }^{a}$ Fábio S. Grasel, ${ }^{\circledR b}$ Gevany P. de Pinho ${ }^{a}$ and \\ Flaviano O. Silvério ${ }^{\circledR} * a$ \\ anstituto de Ciências Agrárias, Universidade Federal de Minas Gerais, \\ 39404-547 Montes Claros-MG, Brazil \\ ${ }^{b}$ Instituto de Química, Universidade Federal do Rio Grande do Sul, \\ 90040-040 Porto Alegre-RS, Brazil
}

\begin{abstract}
The chemical composition of Acacia mearnsii wood extract is described in this paper for the first time. This wood is cultivated in Brazil and has been used to complement the demand for hardwood in the pulp industry. In this study, we performed extractions with acetone (total extracts) and dichloromethane (lipophilic extracts responsible for the pitch formation), with the obtained percentages being 1.68 and $0.68 \%$, respectively. The lipophilic extracts were derivatized and analyzed by Fourier transform infrared spectroscopy (FTIR) and gas chromatographymass spectrometry (GC-MS) before and after alkaline hydrolysis. The results showed that 57 compounds were detected in the lipophilic extracts and these are mainly constituted by fatty acids ca. $32.8 \mathrm{mg} \mathrm{kg}^{-1}$ and sterols $26.9 \mathrm{mg} \mathrm{kg}^{-1}$. These chemical classes have always been present in pitch deposits in the pulp industry. Therefore, these results may be used by pulp mills to establish strategies for pitch control and represent an important advance in the knowledge of A. mearnsii.
\end{abstract}

Keywords: black wattle, mimosa, pitch, wood extract

\section{Introduction}

Acacia mearnsii, popularly known as black wattle or mimosa, is a medium-sized tree in the Fabaceae (Leguminosae) family, native to southeastern Australia, being the only temperate Acacia specie grown commercially on a significant international scale, as it presents high productivity and fast adaptation to different environmental conditions. ${ }^{1-4}$

The species was introduced in several countries around the world in the second half of the $19^{\text {th }}$ century, mainly as a source of fuel, but it was the initial success and first exports of plantation tannins in South Africa that stimulated international interest in the species. ${ }^{2}$

A. mearnsii wood usually has high density and low lignin content that provides a high yield and cellulosic pulp which is easily delignified and bleached..$^{5,6}$ These characteristics confer economic advantages for pulp production, as well as transportation and storage. ${ }^{2}$

Currently, A. mearnsii cultivation mainly occurs in South Africa and southern Brazil, constituting the two

*e-mail: flavianosilverio@ufmg.br main producers of this specie in the world today. ${ }^{7-9}$ The production of these two countries has mainly been exported to Japan and more recently to China for manufacturing kraft pulps and bleached hardwood kraft pulp. ${ }^{2}$ One of the frequently occurring problems in pulp and paper manufacturing in these companies is caused by lipophilic extracts from wood, also known as wood resin or pitch. ${ }^{10-13}$

Although the content of lipophilic extracts is in the range of 2 to $4 \%$ of the hardwood mass, the total removal of these compounds is not always successfully achieved under the conditions of obtaining cellulose pulp in most of them..$^{14,15}$ Therefore, the smallest possible amount of these constituents remaining in the pulping step is highly desirable to minimize fouling problems formed by extracts in bleaching steps and further processing of the pulp..$^{10,16,17}$

This resin is liberated from the pulp during the screening, beating and refining processes and tends to accumulate as an insoluble colloidal suspension with a dark color. These particles cause encrustations in the pulp and paper industries, causing a reduction in production, an increase in equipment maintenance costs and a significant increase in imperfections in the final product, which leads to a fall in product quality. ${ }^{18}$ 
Traditionally, companies reduce pitch problems by preventing their formation during the paper making or pulping processes. This has been accomplished in the pulping process by adding various pitch control agents, e.g., talc, chemical sequestrants, dispersing agents or surfaceactive agents to the pulp during washing, screening and/or bleaching operations. ${ }^{18}$

Thus, knowledge of the quantity and the chemical composition of these lipophilic extracts will be a great contribution to optimizing the industrial process for preventing and controlling pitch deposition during pulp bleaching. In addition, no research has been carried out on the chemical composition of the lipophilic extracts of this important specie from plantations in Brazil. Within this context, the objective of this work was to characterize the chemical composition of the lipophilic extracts from A. mearnsii wood cultivated in Brazil through gas chromatography-mass spectrometry (GC-MS) and Fourier transform infrared spectroscopy (FTIR) analysis.

\section{Experimental}

\section{Samples}

Acacia mearnsii wood samples were obtained from a 7-year-old plantation in Brazil. The wood material used was bark free, chopped into small pieces (industrial size), and air-dried at ambient temperature for 5 days. It was then ground to pass through a 1-mm sieve screened in a vibratory sieving apparatus and 40- to 60-mesh fractions were used for chemical analysis, according to the experimental procedures described in the Tappi standard process (T $264 \mathrm{~cm}-97) .{ }^{19}$

\section{Extraction}

The air-dried powdered samples $(8.00 \mathrm{~g})$ were extracted with acetone for $6 \mathrm{~h}$ using a Soxhlet apparatus, following the adapted Tappi standard process (T $264 \mathrm{~cm}-97$ ). ${ }^{19}$ The solvent was removed under reduced pressure in a rotary evaporator and the fractions were weighed. All extractions were carried out in triplicate and the extraction yields were expressed as percentages in relation to the wood's dry weight.

The same procedure was performed for the lipophilic extract, using dichloromethane as solvent. The lipophilic residue was derivatized and analyzed by GC-MS before and after hydrolysis, as described below. The lipophilic residues before and after hydrolysis were also analyzed by FTIR. All steps in the procedure are shown in the flowchart of Figure S1 (Supplementary Information (SI) section).

\section{Alkaline hydrolysis}

An aliquot of $20.00 \mathrm{mg}$ of lipophilic extract was added to a two-neck round-bottomed flask $(10 \mathrm{~mL})$, followed by $1.8 \mathrm{~mL}$ aqueous solution of $\mathrm{KOH}\left(3 \mathrm{~mol} \mathrm{~L}^{-1}\right)$ and $0.2 \mathrm{~mL}$ of methanol. The mixture was refluxed under a nitrogen atmosphere for $1 \mathrm{~h}$. It was then cooled to room temperature, acidified with aqueous solution of $\mathrm{HCl}\left(3 \mathrm{~mol} \mathrm{~L}^{-1}\right)$ to pH ca. 2 and extracted with dichloromethane $(3 \times 2 \mathrm{~mL})$. The combined organic fractions were dried over anhydrous $\mathrm{MgSO}_{4}$, filtered, and the solvent was completely removed under reduced pressure in a rotary evaporator. ${ }^{20}$

The aqueous fraction was also dried under reduced pressure in a rotary evaporator. The obtained residue was derivatized and analyzed by GC-MS and FTIR.

\section{Derivatization}

Aliquots of hydrolyzed and non-hydrolyzed lipophilic extract $(3.00 \mathrm{mg})$ were dissolved in pyridine $(60 \mu \mathrm{L})$ in capped vials followed by the addition of $100 \mu \mathrm{L}$ $\mathrm{N}, \mathrm{O}$-bis(trimethylsilyl)-trifluoroacetamide (BSTFA) containing $1 \%$ chlorotrimethylsilane (TMSCl). The reaction mixture was heated at $70{ }^{\circ} \mathrm{C}$ for $30 \mathrm{~min}$. It was then cooled to room temperature before conducting GC-MS analysis. This process was repeated with aqueous phase residue obtained after hydrolysis.

\section{GC-MS analysis}

GC-MS analyzes were performed on a gaschromatograph from Agilent Technologies (7890A GC) coupled with mass-spectrometry (MS5975C). A DB5-MS capillary column (Agilent Technologies) was employed with stationary phase of fused silica composed of 5\% phenyl and $95 \%$ dimethylsiloxane with a length of $30 \mathrm{~m}, 0.25 \mathrm{~mm}$ internal diameter, and a $0.25 \mu \mathrm{m}$ film thickness. Helium (99.9999\% purity) was used as carrier gas at a flow rate of $1 \mathrm{~mL} \mathrm{~min}^{-1}$, the injector division rate (split) was 1:10, with an injected volume of $1 \mu \mathrm{L}$. The chromatographic conditions were as follows: injector temperature of $290{ }^{\circ} \mathrm{C}$, initial oven temperature at $80^{\circ} \mathrm{C}$ (5 min), temperature increase rate of $4{ }^{\circ} \mathrm{C} \mathrm{min}^{-1}$, and final temperature of $285{ }^{\circ} \mathrm{C}$ (40 min). The detector and interface temperature were $290{ }^{\circ} \mathrm{C}$. The mass detector was operated with ionization for electron impact $(70 \mathrm{eV})$ and quadrupole mass analyzer, operating with a scan range of 30-600 Da. Identification of the extract components was performed by comparison with the mass spectra database (NIST 2.0) with data from the literature, and by injection standards when necessary. 
For semi-quantitative analysis, the GC-MS equipment was calibrated with pure reference compounds, representative of the major extractive components. Reagents of 97-99\% purity obtained from Sigma-Aldrich (Milwaukee, WI, USA) were: hexadecanoic acid, dodecan1 -ol, trans-ferulic acid and $\beta$-sitosterol. The calibration was relative to hexanedioic acid and tetracosane (99\% purity obtained from Sigma-Aldrich, Milwaukee, USA), with $0.2081 \mathrm{mg} \mathrm{mL}^{-1}$ being used as the internal concentration standard. The response factors needed to obtain the correct quantification of the peak areas were calculated as an average of the five GC-MS runs with the standard compound concentration of $0.2081 \mathrm{mg} \mathrm{mL}^{-1}$, after silylation with BSTFA.

\section{Fourier transform infrared spectroscopy (FTIR)}

The lipophilic extract before and after hydrolysis was submitted to infrared spectroscopy on an Agilent Technologies 640 spectrometer and recorded in the region of 4000 to $500 \mathrm{~cm}^{-1}$ in attenuated total reflection (ATR). Eight accumulations were performed with a resolution of $4 \mathrm{~cm}^{-1}$ in all cases.

\section{Results and Discussion}

Acetone and dichloromethane extractions were carried out in order to read the total amount of polar and lipophilic extracts. The total amount of extract soluble in acetone from A. mearnsii wood was $1.68 \pm 0.01 \%(\mathrm{~m} / \mathrm{m})$. This value is much lower than the values found for E. camaldulensis (3.72\%) and E. urophylla (2.93\%), and it is slightly higher than E. urograndis $(1.32 \%)$ and E. globulus $(1.52 \%){ }^{20,21}$

Pulp and paper companies may use this value when operational procedures in the pulping process are needed to be established in order to control pitch formation. ${ }^{22}$ However, this value does not necessarily correspond to the higher content of lipophilic extracts, since acetone may extract polar compounds as carbohydrates, aromatic compounds among others. ${ }^{22}$ In general, polar compounds are not associated with the formation of pitch deposits. ${ }^{23}$ Therefore, several companies use the extract content soluble in dichloromethane, because this solvent predominantly extracts apolar compounds. These components have direct relation with the formation of pitch deposits. ${ }^{24}$

The percentage of lipophilic extract soluble in dichloromethane from A. mearnsii wood was $0.68 \pm 0.01 \%$ $(\mathrm{m} / \mathrm{m})$. This result is below those found for $B$. verrucosa and A. mangium (1.31 and $1.32 \%$, respectively) and above the values found for E. camaldulensis $(0.47 \%)$, E. urograndis $(0.38 \%)$, and E. urophylla $(0.48 \%))^{21,25}$ Other studies have shown that E. globulus and E. grandis species presented slightly lower results of 0.26 and $0.36 \%$, respectively. ${ }^{20,26,27}$ The lipophilic extract may generate pitch deposits within a paper and cellulose industry, so wood with lower levels of lipophilic extract promote less pitch episodes in these industries.

Although the results found for A. mearnsii are slightly higher than that found for eucalyptus wood, it should be considered that the storage time, genetic improvement, geographical and climatic conditions have a direct influence on the extract concentration. ${ }^{16,28}$ In a study carried out for eucalyptus, the authors showed that the storage time of 180 days can reduce up to $70 \%$ of lipophilic extracts due to biological decomposition and exposure to weathering. ${ }^{13}$

In this context, we considered that the A. mearnsii lipophilic extracts were analyzed from the fresh material without remaining in stock.

\section{FTIR analysis}

The extracts soluble in acetone are predominantly composed of polar compounds, so FTIR spectra predominantly present polar compound signals, as can be seen in Figure S2 (SI section). Therefore, we characterize the soluble extracts in dichloromethane in detail by FTIR and GC-MS, as these are directly related to pitch formation.

The FTIR spectra of the lipophilic extracts before and after hydrolysis are shown in Figure 1, as well as the residue of the aqueous phase after hydrolysis.

All spectra (Figures 1a, 1b and 1c) show absorption bands in the region at 2984 to $2823 \mathrm{~cm}^{-1}$ attributed to sp ${ }^{3}$ carbon $\mathrm{C}-\mathrm{H}$ stretches, which are $\mathrm{CH}, \mathrm{CH}_{2}$ and $\mathrm{CH}_{3}$ groups common in various classes of aliphatic compounds such as fatty esters, free fatty acids and lipophilic alcohols. ${ }^{10,29}$

An absorption region at $1745-1710 \mathrm{~cm}^{-1}$ representing the $\mathrm{C}=\mathrm{O}$ stretch of carbonyl compounds is observed in Figure 1a, being common in free fatty acids, aldehydes and fatty esters. ${ }^{29}$ An absorption band in the extract spectrum after hydrolysis and the residue of the aqueous phase (Figures $1 \mathrm{~b}$ and $1 \mathrm{c}$ ) can only be observed at $1710 \mathrm{~cm}^{-1} .^{10,29}$ The absorption band at $1745 \mathrm{~cm}^{-1}$ could not be detected because fatty esters were totally hydrolyzed, indicating the hydrolysis efficiency of this class of compounds.

Absorption at $1463 \mathrm{~cm}^{-1}$ can be observed in both spectra, corresponding to the symmetrical $\left(\mathrm{CH}_{2}\right)$ and asymmetrical $\left(\mathrm{CH}_{3}\right)$ in-plane angular deformation band. The band at $1382 \mathrm{~cm}^{-1}$ in Figure 1a can be attributed to symmetrical in-plane angular deformation $\left(\mathrm{CH}_{3}\right)$. In this same figure, the bands at 1232, 1160 and $1021 \mathrm{~cm}^{-1}$ can be attributed to the $\mathrm{C}-\mathrm{O}$ stretch of esters, so they only appear in the spectrum of Figure 1a. 

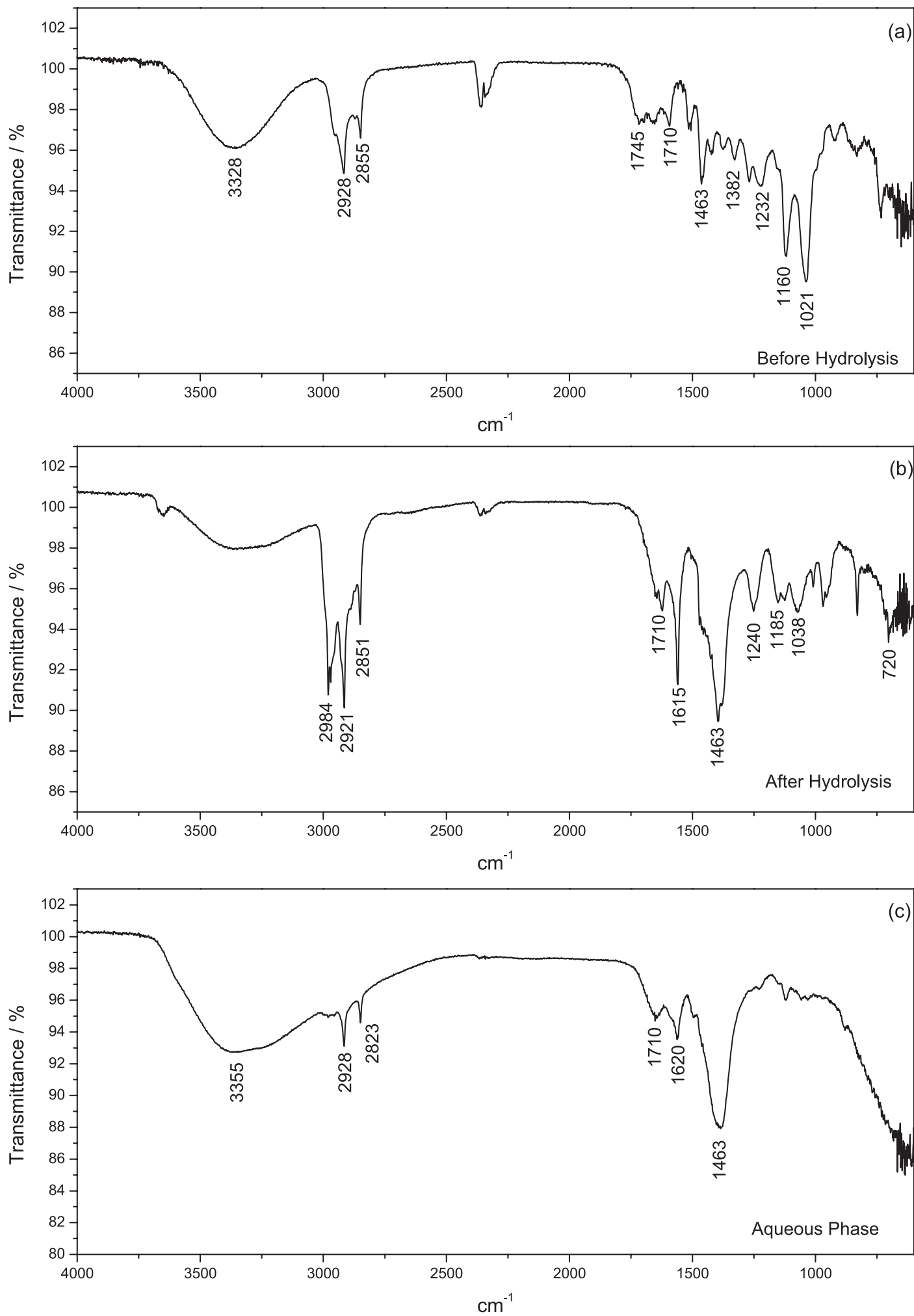

Figure 1. Infrared spectra (ATR) of the A. mearnsii wood extract (a) before and (b) after hydrolysis, and (c) the residue of the aqueous phase after hydrolysis.

In the extract spectrum after hydrolysis (Figure 1b), the bands at 1240,1185 and $1038 \mathrm{~cm}^{-1}$ are attributed to the $\mathrm{C}-\mathrm{O}$ stretch of free fatty acid. This spectrum can be observed in the absorption band at $720 \mathrm{~cm}^{-1}$, corresponding to the in- plane angular deformation, swing type $(\rho)$, characteristic of compounds with groups $\left[\mathrm{CH}_{2}\right]_{\mathrm{n}}$, with $\mathrm{n} \geq 4 . .^{29}$

The presence of $\mathrm{O}-\mathrm{H}$ stretching broadband between $3400-2500 \mathrm{~cm}^{-1}$ indicates the presence of free fatty acids 
and fatty alcohols. ${ }^{10,29}$ The absorption band is broader in Figures $1 \mathrm{~b}$ and $1 \mathrm{c}$ than in Figure 1a, probably due to the presence of more $\mathrm{O}-\mathrm{H}$ groups of acidic and alcohol compounds generated after the hydrolysis.

In general, this FTIR spectrum confirms the presence of free fatty acid, aldehydes and fatty esters before the hydrolysis (Figure 1a). Figures $1 \mathrm{~b}$ and $1 \mathrm{c}$ confirm the absence of fatty esters and the presence of free fatty acid and aliphatic alcohol, as well as a small percentage of lipophilic extracts in the residue of the aqueous phase (Figure 1c).

The commercial production of cellulose today is mainly based on alkaline processes. Kraft pulping is the most widely used process to produce chemical pulps, where the wood chips are treated with a strong alkaline solution at temperatures above $150{ }^{\circ} \mathrm{C}$. In this way, the identification of liposoluble extracts after hydrolysis is of extreme importance, because the main current processes of dissolving pulp are extremely favorable for their formation. . $^{30-32}$

These extracts before and after hydrolysis and the residue of the aqueous phase were analyzed by GC-MS to determine the detailed chemical composition of each extract.

The presence of hydroxyl groups in extracts before and after hydrolysis and in the aqueous phase residue after hydrolysis is required prior to derivatizing the extracts with BSTFA to obtain trimethylsilyl esters.

\section{GC-MS analysis}

Figure 2 shows a typical total ion chromatogram obtained for lipophilic extracts from A. mearnsii wood, before and after hydrolysis. The residue of the aqueous fraction was also analyzed due to the presence of polar compounds such as short chain fatty acids and alcohols.

A list of the identified compounds and their quantification is shown in Table 1, in which 57 compounds were detected in the analyzed chromatograms. The identified components in the residue of the aqueous fraction are also shown in Table 1.

It can be seen that approximately $83.4 \%$ of the 57 compounds detected in the lipophilic extract of A. mearnsii wood were identified. This value is much higher than the percentage of compounds identified in the E. globulus (44.6\% after hydrolysis), E. urograndis (50\% after hydrolysis), and E. camaldulensis ( $41 \%$ after hydrolysis) extracts. ${ }^{21,27}$

These compounds identified in the hydrolyzed and nonhydrolyzed extracts were grouped into four main classes according to their chemical structures, as shown in Figure 3.
We may also see an increase in the total amount of lipophilic extracts detected by GC-MS after alkaline hydrolysis (Table 1, Figure 3), particularly among the fatty acids. This confirms the presence of a significant amount of esterified structures such as stearyl esters, glycerides, and waxes, among others. This result is similar to previous works with eucalyptus wood. ${ }^{12,20,21,33}$ These esterified structures have already been identified in pitch deposits. ${ }^{10,11,24,27}$

Fatty acids represented the major class of nonpolar components present in the lipophilic extract after hydrolysis, being constituted by saturated, unsaturated and hydroxy acids, as may be observed in Figure 4. The amount of fatty acids (20.1 and $32.9 \mathrm{mg} \mathrm{kg}^{-1}$, respectively) before and after hydrolysis was similar to that of the E. globulus wood extracts $\left(27.7 \mathrm{mg} \mathrm{kg}^{-1}\right),{ }^{20}$ and significantly lower than those found in the lipophilic extracts from E. urophylla (ca. $338 \mathrm{mg} \mathrm{kg}^{-1}$ ), E. urograndis (ca. $946 \mathrm{mg} \mathrm{kg}^{-1}$ ) and E. camaldulensis (ca. $1070 \mathrm{mg} \mathrm{kg}^{-1}$ ). ${ }^{21}$ This low content of fatty acids represents the main advantage of A. mearnsii wood in relation to Eucalyptus wood from the perspective of pitch formation.

It can be seen that saturated fatty acids were predominant over unsaturated and hydroxy fatty acids. Within the saturated fatty acids, we can highlight the hexadecanoic acid (palmitic acid), docosanoic acid, and tetracosanoic acid as the main components. The $(9 Z, 12 Z)$-octadeca9,12-dienoic acid (linoleic acid) and (Z)-octadec-9-enoic acid (oleic acid) were the major components of unsaturated fatty acids. These results are in agreement with previous works for lipophilic extracts from Eucalyptus wood. 12,20,21 However, the detected amount of these compounds in the extracts from A. mearnsii wood was lower than that detected in lipophilic extracts from E. urograndis, E. urophylla and E. camaldulensis wood. ${ }^{21}$

GC-MS analysis also enabled identification of several $\alpha$ and $\omega$-hydroxy fatty acids in small quantities in the lipophilic extracts from A. mearnsii wood. These compounds have already been detected in lipophilic extracts of Eucalyptus wood and commonly found as abundant components of pitch deposits in pulp mills..$^{20,21,27,34}$ However, the significantly lower abundance of these compounds in lipophilic extracts of A. mearnsii wood is a great advantage in terms of pitch formation during the industrial pulping process.

Sterols represent the second largest chemical class detected in lipophilic extracts of A. mearnsii wood. Seven components were detected in lipophilic extracts from A. mearnsii wood in this study, but they were not identified. In general, the main sterols which represent this class, and which occur in the lipophilic extracts from 


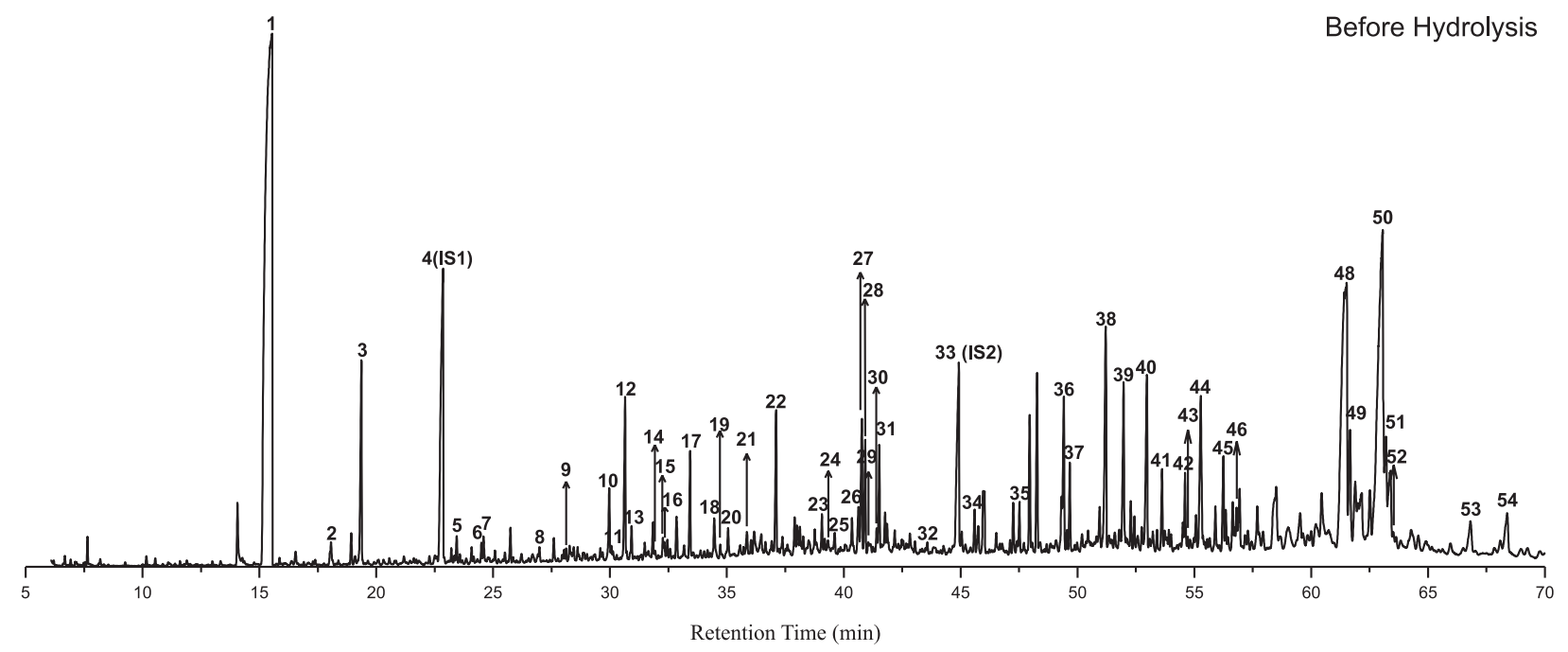

After Hydrolysis
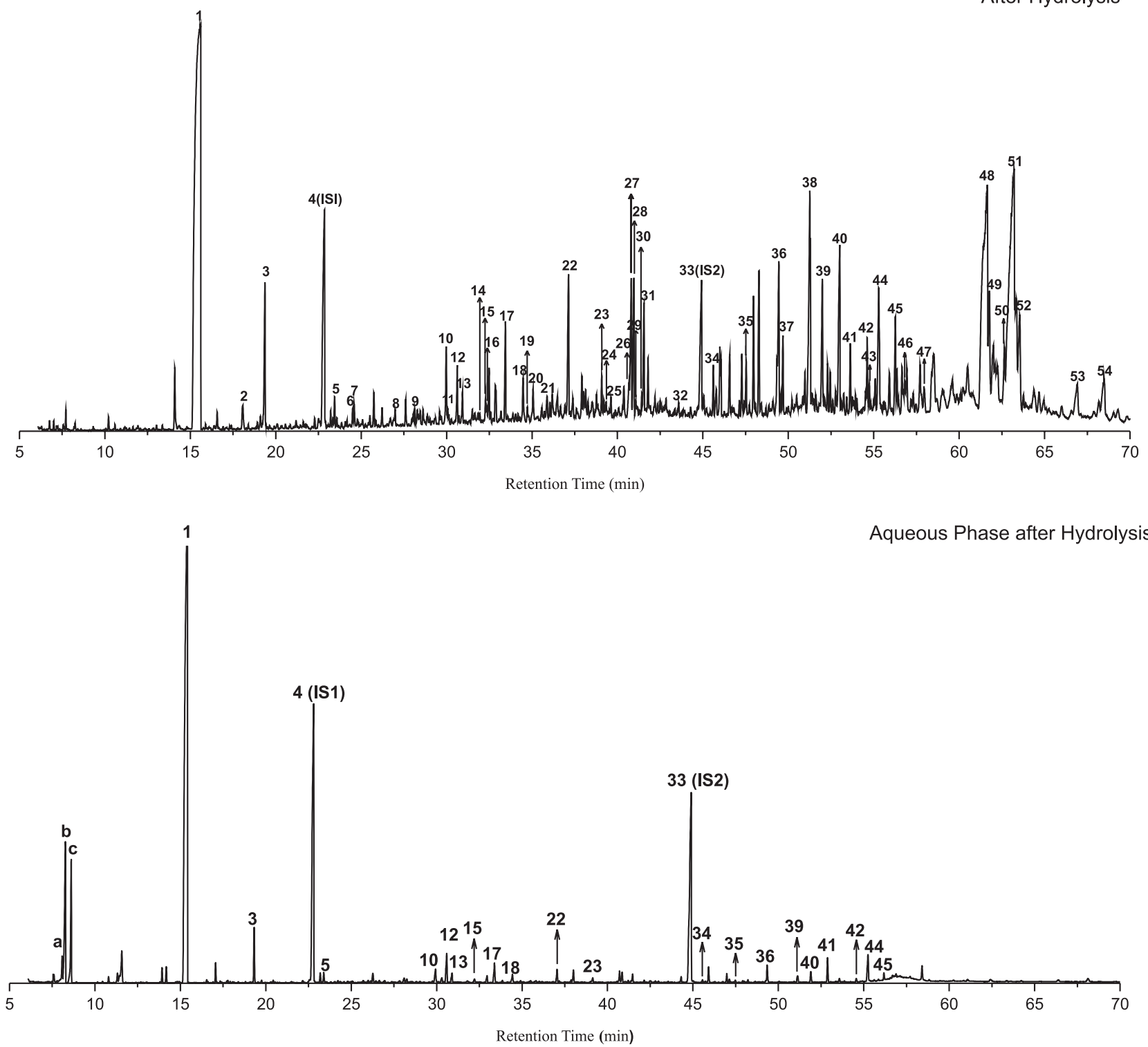

Figure 2. Total ion chromatograms of the derivatized lipophilic extracts of A. mearnsii before and after hydrolysis, and residue of the aqueous phase after hydrolysis. IS1 and IS2 are internal standards. The letters a, b and c are compounds which are only detected in the aqueous phase residue after hydrolysis. 
Table 1. Components (mean value \pm standard deviation) identified in lipophilic extracts from A. mearnsii wood before and after hydrolysis, and residue of the aqueous phase after hydrolysis

\begin{tabular}{|c|c|c|c|c|c|}
\hline \multirow[t]{2}{*}{ Peak } & \multirow[t]{2}{*}{$\mathrm{t}_{\mathrm{R}} / \min$} & \multirow[t]{2}{*}{ Identification } & \multicolumn{2}{|c|}{$\begin{array}{c}\text { Hydrolysis / } \\
\text { (mg of compound per kg of dry wood) }\end{array}$} & \multirow{2}{*}{$\begin{array}{l}\text { Aqueous phase / } \\
\text { (mg of compound per } \\
\text { kg of dry wood) }\end{array}$} \\
\hline & & & Before & After & \\
\hline $\mathrm{a}$ & 8.1 & 2-hydroxypropanoic acid & $\mathrm{Nd}$ & $\mathrm{Nd}$ & $0.16 \pm 0.00$ \\
\hline $\mathrm{b}$ & 8.3 & etanodioic acid & $\mathrm{Nd}$ & $\mathrm{Nd}$ & $1.41 \pm 0.01$ \\
\hline $\mathrm{c}$ & 8.6 & hydroxyacetic acid & $\mathrm{Nd}$ & $\mathrm{Nd}$ & $1.07 \pm 0.00$ \\
\hline 1 & 15.5 & glycerol & $29.25 \pm 0.32$ & $33.91 \pm 0.25$ & $13.19 \pm 0.05$ \\
\hline 2 & 18.1 & nonanoic acid & $0.08 \pm 0.00$ & $0.49 \pm 0.00$ & $\mathrm{Nd}$ \\
\hline 3 & 19.4 & 1,4-dihydroxybenzene & $1.83 \pm 0.02$ & $1.73 \pm 0.01$ & $0.35 \pm 0.00$ \\
\hline 4 & 22.9 & hexanedioic acid (internal standard) & $5.86 \pm 0.00$ & $5.86 \pm 0.00$ & $5.86 \pm 0.00$ \\
\hline 5 & 23.4 & 4-hydroxy-3-methoxybenzaldehyde & $0.34 \pm 0.00$ & $0.50 \pm 0.00$ & $0.07 \pm 0.00$ \\
\hline 6 & 24.5 & decanoic acid & $0.22 \pm 0.00$ & $0.32 \pm 0.00$ & $\mathrm{Nd}$ \\
\hline 7 & 24.6 & dodecan-1-ol & $0.35 \pm 0.00$ & $0.39 \pm 0.00$ & $\mathrm{Nd}$ \\
\hline 8 & 27.0 & dodecanoic acid & $0.15 \pm 0.00$ & $0.56 \pm 0.01$ & $\mathrm{Nd}$ \\
\hline 9 & 28.1 & 4-hydroxy-3,5-dimethoxybenzaldehyde & $0.13 \pm 0.00$ & $0.24 \pm 0.02$ & $\mathrm{Nd}$ \\
\hline 10 & 30.0 & 4-hydroxy-3-methoxbenzoic acid & $0.89 \pm 0.00$ & $1.41 \pm 0.00$ & $0.13 \pm 0.00$ \\
\hline 11 & 30.1 & tetradecan-1-ol & $0.08 \pm 0.00$ & $0.13 \pm 0.00$ & $\mathrm{Nd}$ \\
\hline 12 & 30.6 & 1,4-benzenedicarboxylic acid & $2.42 \pm 0.00$ & $1.11 \pm 0.00$ & $0.35 \pm 0.00$ \\
\hline 13 & 30.9 & nonanedioic acid & $0.40 \pm 0.00$ & $0.77 \pm 0.00$ & $0.14 \pm 0.00$ \\
\hline 14 & 31.9 & 4-hydroxy-3-methoxycinnamaldehyde & $0.06 \pm 0.00$ & $0.15 \pm 0.00$ & $\mathrm{Nd}$ \\
\hline 15 & 32.3 & tetradecanoic acid & $0.15 \pm 0.00$ & $0.29 \pm 0.00$ & $0.06 \pm 0.00$ \\
\hline 16 & 32.3 & aromatic compound $\mathrm{Ni}$ & $0.08 \pm 0.00$ & $0.11 \pm 0.00$ & $\mathrm{Nd}$ \\
\hline 17 & 33.4 & 4-hydroxy-3,5-dimethoxybenzoic acid & $1.42 \pm 0.00$ & $1.89 \pm 0.01$ & $0.24 \pm 0.00$ \\
\hline 18 & 34.5 & 5-allyl-2,3-dihydroxy-1-methoxybenzene & $0.40 \pm 0.00$ & $1.07 \pm 0.00$ & $0.10 \pm 0.00$ \\
\hline 19 & 34.7 & pentadecanoic acid & $0.16 \pm 0.00$ & $0.52 \pm 0.00$ & $\mathrm{Nd}$ \\
\hline 20 & 35.1 & hexadecan-1-ol & $0.40 \pm 0.00$ & $0.98 \pm 0.00$ & $\mathrm{Nd}$ \\
\hline 21 & 35.9 & aromatic compound $\mathrm{Ni}$ & $0.37 \pm 0.00$ & $0.53 \pm 0.00$ & $\mathrm{Nd}$ \\
\hline 22 & 37.1 & hexadecanoic acid & $2.58 \pm 0.00$ & $4.13 \pm 0.01$ & $0.16 \pm 0.00$ \\
\hline 23 & 39.1 & aromatic compound $\mathrm{Ni}$ & $0.29 \pm 0.00$ & $0.44 \pm 0.00$ & $0.12 \pm 0.00$ \\
\hline 24 & 39.3 & heptadecanoic acid & $0.07 \pm 0.00$ & $0.19 \pm 0.00$ & $\mathrm{Nd}$ \\
\hline 25 & 39.6 & octadecan-1-ol & $0.20 \pm 0.00$ & $0.24 \pm 0.00$ & $\mathrm{Nd}$ \\
\hline 26 & 40.6 & 2-hydroxyhexadecanoic acid & $0.45 \pm 0.00$ & $0.20 \pm 0.00$ & $\mathrm{Nd}$ \\
\hline 27 & 40.8 & $(9 Z, 12 Z)$-octadeca-9,12-dienoic acid & $1.54 \pm 0.00$ & $3.25 \pm 0.01$ & $\mathrm{Nd}$ \\
\hline 28 & 40.9 & (Z)-octadec-9-enoic acid & $1.26 \pm 0.00$ & $2.35 \pm 0.01$ & $\mathrm{Nd}$ \\
\hline 29 & 41.1 & (E)-octadec-9-enoic acid & $0.05 \pm 0.00$ & $0.16 \pm 0.00$ & $\mathrm{Nd}$ \\
\hline 30 & 41.4 & 4-hydroxy-3,5-dimethoxycinnamic acid & $0.13 \pm 0.00$ & $0.15 \pm 0.00$ & $\mathrm{Nd}$ \\
\hline 31 & 41.5 & octadecanoic acid & $1.04 \pm 0.00$ & $1.57 \pm 0.01$ & $\mathrm{Nd}$ \\
\hline 32 & 43.6 & nonadecanoic acid & $0.09 \pm 0.00$ & $0.25 \pm 0.00$ & $\mathrm{Nd}$ \\
\hline 33 & 44.9 & tetracosane (internal standard) & $4.99 \pm 0.00$ & $4.99 \pm 0.00$ & $4.99 \pm 0.00$ \\
\hline 34 & 45.6 & icosanoic acid & $0.43 \pm 0.00$ & $0.72 \pm 0.00$ & $0.02 \pm 0.00$ \\
\hline 35 & 47.5 & heneicosanoic acid & $0.41 \pm 0.04$ & $0.65 \pm 0.00$ & $0.01 \pm 0.00$ \\
\hline 36 & 49.4 & docosanoic acid & $1.29 \pm 0.00$ & $3.66 \pm 0.01$ & $0.11 \pm 0.00$ \\
\hline 37 & 49.6 & aromatic compound $\mathrm{Ni}$ & $0.15 \pm 0.00$ & $0.19 \pm 0.00$ & $\mathrm{Nd}$ \\
\hline 38 & 51.2 & terephthalic acid & $2.95 \pm 0.00$ & $5.03 \pm 0.02$ & $\mathrm{Nd}$ \\
\hline 39 & 52.0 & 2-hydroxydocosanoic acid & $2.02 \pm 0.00$ & $2.27 \pm 0.01$ & $0.08 \pm 0.00$ \\
\hline 40 & 53.0 & tetracosanoic acid & $2.54 \pm 0.00$ & $3.62 \pm 0.01$ & $0.17 \pm 0.00$ \\
\hline 41 & 53.6 & 2-hydroxytricosanoic acid & $0.89 \pm 0.00$ & $0.01 \pm 0.00$ & $0.02 \pm 0.00$ \\
\hline 42 & 54.6 & pentacosanoic acid & $0.66 \pm 0.00$ & $1.31 \pm 0.00$ & $0.03 \pm 0.00$ \\
\hline 43 & 54.7 & hexacosan-1-ol & $0.08 \pm 0.00$ & $0.29 \pm 0.00$ & $\mathrm{Nd}$ \\
\hline 44 & 55.2 & $\begin{array}{l}\text { 2-hidroxytetracosanoic acid and } \\
\text { 22-hydroxydocosanoic acid }\end{array}$ & $2.43 \pm 0.00$ & $2.84 \pm 0.01$ & $0.26 \pm 0.00$ \\
\hline 45 & 56.2 & hexacosanoic acid & $0.96 \pm 0.00$ & $1.54 \pm 0.01$ & $0.05 \pm 0.00$ \\
\hline
\end{tabular}


Table 1. Components (mean value \pm standard deviation) identified in lipophilic extracts from A. mearnsii wood before and after hydrolysis, and residue of the aqueous phase after hydrolysis (cont.)

\begin{tabular}{lccccc}
\hline Peak & & Identification & \multicolumn{2}{c}{$\begin{array}{c}\text { Hydrolysis / } \\
\text { Aqueous phase / } \\
\text { (mg of compound per kg of dry wood) }\end{array}$} & $\begin{array}{c}\text { (mg of compound per } \\
\text { kg of dry wood) }\end{array}$ \\
\cline { 3 - 7 } & & & Before & After & After hydrolysis \\
\hline 46 & 56.8 & 23-hydroxytricosanoic acid & $0.20 \pm 0.00$ & $0.20 \pm 0.00$ & $\mathrm{Nd}$ \\
47 & 57.9 & octacosan-1-ol & $\mathrm{Nd}$ & $0.50 \pm 0.00$ & $\mathrm{Nd}$ \\
48 & 61.5 & steroid Ni & $10.35 \pm 0.01$ & $11.53 \pm 0.04$ & $\mathrm{Nd}$ \\
49 & 61.7 & steroid Ni & $1.16 \pm 0.00$ & $1.05 \pm 0.00$ & $\mathrm{Nd}$ \\
50 & 62.6 & steroid Ni & $0.62 \pm 0.00$ & $0.57 \pm 0.00$ & $\mathrm{Nd}$ \\
51 & 63.1 & steroid Ni & $9.58 \pm 0.01$ & $10.05 \pm 0.03$ & $\mathrm{Nd}$ \\
52 & 63.5 & steroid Ni & $0.06 \pm 0.00$ & $1.49 \pm 0.00$ & $\mathrm{Nd}$ \\
53 & 66.9 & steroid Ni & $0.65 \pm 0.00$ & $1.11 \pm 0.00$ & $\mathrm{Nd}$ \\
54 & 68.4 & steroid Ni & $0.79 \pm 0.00$ & $1.19 \pm 0.00$ & $\mathrm{Nd}$ \\
\hline
\end{tabular}

$\mathrm{t}_{\mathrm{R}}$ : retention time; Ni: non-identified; Nd: non-detected.

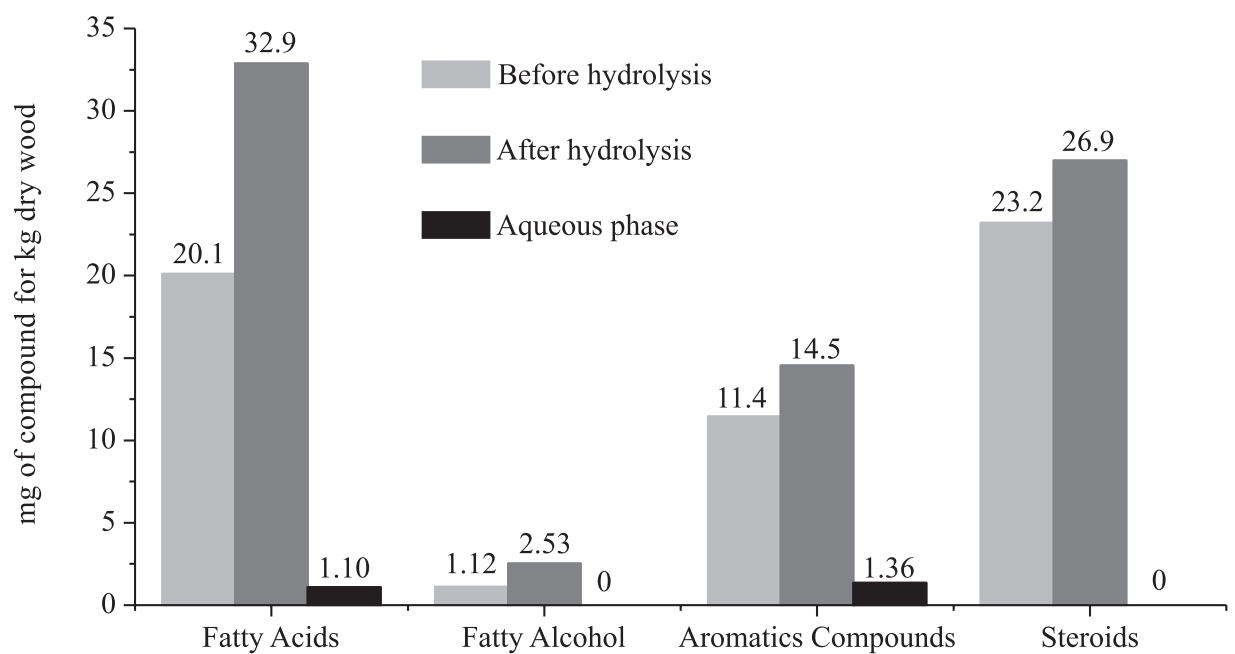

Figure 3. Major chemical classes of identified compounds in the lipophilic extracts of A. mearnsii wood before and after hydrolysis, and residue of the aqueous phase after hydrolysis.

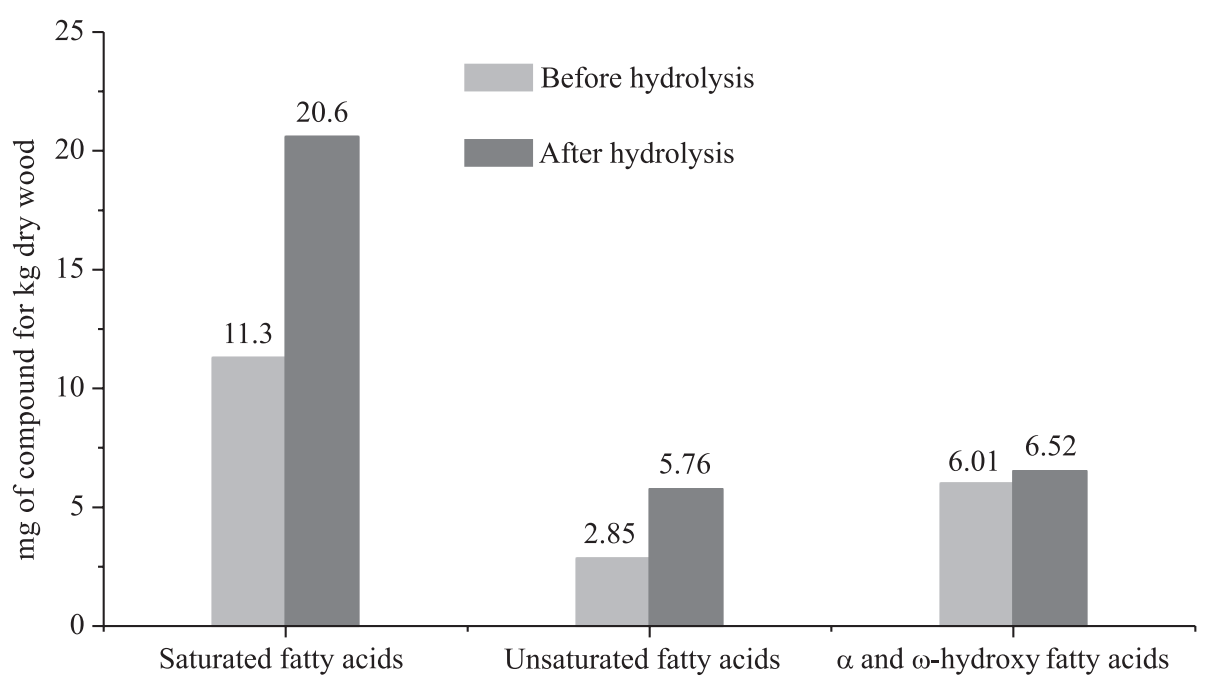

Figure 4. Main fatty acids present in the lipophilic extract of A. mearnsii wood before and after hydrolysis. 
Eucalyptus wood are $\beta$-sitosterol and $\beta$-sitostanol. ${ }^{12,20,21}$ It can be observed that the content of this chemical class also increased after hydrolysis. This result showed that sterols are mainly present in esterified form in the extracts, as occurs with the extracts from Eucalyptus wood.

The amount of sterols found in the lipophilic extract from A. mearnsii wood were 23.2 and $26.9 \mathrm{mg} \mathrm{kg}^{-1}$, before and after hydrolysis, respectively. These values were significantly lower than those found in the extracts from Eucalyptus wood. ${ }^{21}$ Previous studies have presented sterol levels for E. globulus, E. urograndis, E. urophylla and E. camaldulensis of $645,800,274$, and $686 \mathrm{mg} \mathrm{kg}^{-1}$, respectively. ${ }^{20,21}$ These values represent an important advantage of the A. mearnsii wood over Eucalyptus wood from the perspective of pitch deposit formation.

Aromatic compounds represent the third largest chemical class detected in lipophilic extracts from A. mearnsii wood. The aromatic composition of the studied A. mearnsii extracts is more complex than that reported for E. urophylla, E. globulus, E. urograndis, and E. camaldulensis. ${ }^{20,21,27}$ These compounds were not abundant in pitch deposits, so the amount detected in this wood does not represent a problem from the pitch formation perspective.

Long-chain fatty alcohols represented a small portion of the total lipophilic extract identified by GC-MS (Figure 3). Dodencan-1-ol, tetradecan-1-ol, hexadecan1-ol, octadecan-1-ol, hexacosan-1-ol, and octacosan-1-ol were the main alcohols found in the analyzed extract. These compounds were reported in previous studies as components of eucalyptus wood extracts. ${ }^{12,21,27,34}$ Previous works also detected this chemical class in pitch deposits. ${ }^{24}$ Therefore, the small amounts of these compounds in lipophilic extracts from A. mearnsii wood is an important parameter from the perspective of pitch deposit formation.

In the aqueous phase, steroids and long-chain fatty alcohols were not detected. The main chemical classes detected were fatty acids $\left(1.10 \mathrm{mg} \mathrm{kg}^{-1}\right)$ and aromatic compounds $\left(1.36 \mathrm{mg} \mathrm{kg}^{-1}\right)$. These values were significantly lower than in the organic phase after hydrolysis (see Figure 3). Compounds identified in this residue were the same as those detected in the lipophilic extracts before and after hydrolysis. Only three compounds (2-hydroxypropanoic acid, ethanoic acid and hydroxyacetic acid) were detected in this residue. These compounds are highlighted in the chromatogram as $\mathrm{a}, \mathrm{b}$ and $\mathrm{c}$ compound (Figure 2 and Table 1). However, these three compounds have no contribution from the point of view of pitch formation.

Further research will be required to evaluate the effects of lipophilic extract from A. mearnsii wood during the pulping and bleaching stages.

\section{Conclusions}

This study described the detailed chemical composition of lipophilic extracts from A. mearnsii wood for the first time. The results showed qualitative chemical composition similar to the extracts from Eucalyptus wood. However, from a quantitative point of view, this wood had lower levels in relation to Eucalyptus wood, mainly being smaller amounts of fatty acids and steroids. The quantification and identification of these chemical classes are important because they have always been detected in pitch deposits, and smaller amounts of these compounds indicate less need to add chemicals, thus avoiding overdoses, in addition to less severe conditions of process control. Therefore, this is the main advantage of A. mearnsii wood in relation to Eucalyptus wood.

\section{Supplementary Information}

Supplementary data are available free of charge at http://jbcs.sbq.org.br as PDF file.

\section{Acknowledgments}

The authors thank the Conselho Nacional de Desenvolvimento Científico e Tecnológico (CNPq) (420637/2016-8) for the financial support from research fellowships. The authors are also grateful to the Fundação de Amparo à Pesquisa do Estado de Minas Gerais (FAPEMIG) (APQ-01429-16), Coordenação de Aperfeiçoamento de Pessoal de Nível Superior (CAPES) and the Universidade Federal de Minas Gerais (UFMG) for the infrastructure provided. The authors thank the Tanac SA company for sending the samples.

\section{References}

1. Menezes, C. M.; da Costa, A. B.; Renner, R. R.; Bastos, L. F.; Ferrão, M. F.; Dressler, V. L.; Anal. Methods 2014, 6, 8299.

2. Chan, J. M.; Day, P.; Feely, J.; Thompson, R.; Little, K. M.; Norris, C. H.; South. For. 2015, 77, 19.

3. Searle, S. In Technical Paper - Division of Forestry; Division of Forestry and Forest Products, CSIRO: Clayton, Australia, 1991, p. 38.

4. Grasel, F. S.; Behrens, M. C.; Strassburger, D.; Einloft, S. O.; Diz, F. M.; Morrone, F. B.; Wolf, C. R.; Ligabue, R. A.; Braz. J. Chem. Eng. 2019, 36, 239.

5. Santos, A.; Anjos, O.; Simões, R.; Silva Lusitana 2005, 13, 249.

6. Muneri, A.; South. Afr. For. J. 1997, 179, 13.

7. Chen, C.; Duan, C.; Li, J.; Liu, Y.; Ma, X.; Zheng, L.; Stavik, J.; Ni, Y.; BioResources 2016, 11, 5553. 
8. Griffin, A. R.; Midgley, S. J.; Bush, D.; Cunningham, P. J.; Rinaudo, A. T.; Divers. Distrib. 2011, 17, 837.

9. Grasel, F. S.; Marcelo, M. C. A.; Ferrão, M. F.; Anal. Methods 2017, 9, 3977.

10. Cruz, M. P.; Barbosa, L. C. A.; Maltha, C. R. A.; Gomide, J. L.; Milanez, A. F.; Quim. Nova 2006, 29, 459.

11. Del Río, J. C.; Gutiérrez, A.; González-Vila, F. J.; Martín, F.; Romero, J.; J. Chromatogr. A 1998, 823, 457.

12. Silvério, F. O.; Barbosa, L. C. A.; Maltha, C. R. A.; Silvestre, A. J. D.; Veloso, D. P.; Gomide, J. L.; BioResources 2007, 2, 157.

13. Silvério, F. O.; Barbosa, L. C. A.; Maltha, C. R. A.; Fidêncio, P. H.; Cruz, M. P.; Veloso, D. P.; Milanez, A. F.; Bioresour. Technol. 2008, 99, 4878.

14. Del Río, J.; Gutiérrez, A.; González-Vila, F.; Martín, F.; J. Anal. Appl. Pyrolysis 1999, 49, 165.

15. Silvério, F. O.; Barbosa, L. C. A.; Fidêncio, P. H.; Cruz, M. P.; Maltha, C. R. A.; Piló-Veloso, D.; J. Wood Chem. Technol. 2011, 31, 26.

16. Dorado, J.; Claassen, F. W.; Van Beek, T. A.; Lenon, G.; Wijnberg, J. B. P.; Sierra-Alvarez, R.; J. Biotechnol. 2000, 80, 231.

17. Martínez-Íñigo, M.; Gutiérrez, A.; Del Río, J.; Martínez, M.; Martínez, A.; J. Biotechnol. 2000, 84, 119.

18. Lipowski, S. A.; Hern, J. F.; U.S. Patent No. 3,582,461 1971.

19. Tappi T 264 cm-97: Preparation of Wood for Chemical Analysis; Tappi Press, Atlanta, 1997.

20. Gutiérrez, A.; Del Río, J. C.; González-Vila, F. J.; Martín, F.; Holzforschung 1999, 53, 481.
21. Silvério, F. O.; Barbosa, L. C. A.; Silvestre, A. J.; Veloso, D. P.; Gomide, J. L.; J. Wood Sci. 2007, 53, 533.

22. Barbosa, L. C. A.; Maltha, C. R. A.; Cruz, M. P.; Sci. Eng. J. 2005, 15, 13 .

23. Sjostrom, E.; Alen, R.; Analytical Methods in Wood Chemistry, Pulping and Paperking; Springer: Berlin, Germany, 1998.

24. Gutiérrez, A.; Del Río, J. C.; Bioresour. Technol. 2005, 96, 1445.

25. Freire, C. S.; Pinto, P. C.; Santiago, A. S.; Silvestre, A. J.; Evtuguin, D. V.; Neto, C. P.; BioResources 2006, 1, 3.

26. Gutiérrez, A.; Del Río, J. C.; González-Vila, F. J.; Martín, F.; J. Chromatogr. A 1998, 823, 449.

27. Freire, C. S. R.; Silvestre, A. J. D.; Neto, C. P.; Holzforschung 2002, 56, 143.

28. Ramnath, L.; Sithole, B.; Govinden, R.; BioResources 2018, $13,86$.

29. Silvério, F. O.; Barbosa, L. C. A.; Gomide, J. L.; Reis, F. P.; Piló-Veloso, D.; Rev. Arvore 2006, 30, 1009.

30. Zanão, M.; Colodette, J. L.; Oliveira, R. C.; Almeida, D. P.; Gomes, F. J.; Carvalho, D. M. D.; J. Wood Chem. Technol. 2019, $39,149$.

31. Ribeiro, R. A.; Colodette, J. L.; Vaz Jr., S.; Cerne 2018, 24, 408.

32. Schimleck, L. R.; Kube, P. D.; Raymond, C. A.; Can. J. For. Res. 2004, 34, 2363.

33. Benouadah, N.; Pranovich, A.; Aliouche, D.; Hemming, J.; Smeds, A.; Willför, S.; Holzforschung 2018, 72, 97.

34. Silvestre, A. J. D.; Pereira, C. C. L.; Neto, C. P.; Evtuguin, D. V.; Duarte, A. C.; Cavaleiro, J. A. S.; Furtado, F. P.; Appita J. 1999, 52, 375 . 